In case of succinyl choline, we did not obtain epileptic convulsion through c.s.f., but we obtained it when about $5 \mathrm{mg}$ of succinyl choline powder were applied directly to the motor cortex of non-curarized animals.

Thus, we found that all the quarternary ammoniums which we tested had the action to produce epileptic convulsion when applied into cerebrospinal fluid. (2) Blocking Action of Quarternary Nitrogen

Curare-like action of quarternary nitrogen is well known and it reported by several authors., ${ }^{1,2}$ )

We confirmed that the listed quarternary ammonium had blocking action on neuromuscular junction of cold-blooded animals when diluted than $0.005 \mathrm{M}$ of each in Ringer's solution.

The convulsive action and blocking action of neuromuscular junction would be presumed to have some parallelism.

\title{
REFERENCES
}

1) Riker, W. F. and Wescoe, W. C., Ann. New York Acad. Sci., 54: 373, 1951.

2) Thesleff, S. and Unna, K. R., J. Pharm. Exp. Therap. V. 111, 99-113, 1954.

\section{On the Presence of Carnosine, Homocarnosine, Anserine in the Central Nervous System of Various Animal Species}

\author{
Takashi Hayashi, Genkichiro TaKagaKI, Akikazu TAKada \\ Dept. of Physiology, School of Medicine, Keio University
}

Hayashi et al have established that there were two cortical pathway systems which produced epileptic seizure; pallial seizure system and limbic seizure system, and the former was inhibited by $\gamma$-amino- $\beta$-hydroxy-butyric acid, but the latter, by homocarnosine and carnosine (1963, the annual meeting of J.P.S.).

In 1960, Udenfriend found homocarnosine in beef brain, Hosein carnosine in rat brain.

By means of columnchromatography according Tallan, we studied the presence of carnosine and anserine in the brain of dog, cat, rabbit, rat and guineapig respectively.

These substances had no evidence in dogs and cats, on the contrary, they were found in rabbit, rat and guinea pig, and quantitative analysis was possible.

However, as carnosine and homocarnosine make the same peak on the chromatographic curve, we are studying the separation and the identification of these two substances. 